\title{
Thermal Protection for a Re-Entry Vehicle Using Heat Ablation Process
}

\author{
Suvriti Dhawan ${ }^{1}$, Mohit Vishal' ${ }^{2}$, Anmol Taploo ${ }^{3}$ \\ ${ }^{1,2,3}$ UG Student, Department of Aerospace Engineering, SRM University, Main Campus, Kattankulathur, Chennai-603203, India
}

\begin{abstract}
The purpose of this paper is to study the heat management problem of a re-entry vehicle and how can it be controlled by the means of using an effective heat ablation process. It is very important to determine the type of ablative material to be used, only then it would ensure effective heat shielding.A rocket on re-entry into the earth's atmosphere depends more on friction than the rocket power to slow down and due to this it experiences very high aerodynamic heating. In order to protect the interior of the rocket,its payload and essential electrical motors from damage the rockets have two systems of heat shields-(1)Ablative layer of heat shield and (2)Thermal soak. The Ablative layer is made of plastic resin to protect the outer surface which is heated using a gas which transfers theheat by convection.
\end{abstract}

Keywords: Re- entry Vehicle, Thermal Protection, Thermal Protection System ( TPS),Ablative Materials

\section{Introduction}

The concept of the ablative heat shield was described as early as 1920 by Robert Goddard: "In the case of meteors, which enter the atmosphere with speeds as high as 30 miles per second $(48 \mathrm{~km} / \mathrm{s})$, the interior of the meteors remains cold, and the erosion is due, to a large extent, to chipping or cracking of the suddenly heated surface. For this reason, if the outer surface of the apparatus were to consist of layers of a very infusible hard substance with layers of a poor heat conductor between, the surface would not be eroded to any considerable extent, especially as the velocity of the apparatus would not be nearly so great as that of the average meteor

The heat ablation technique was used effectively by the Mercury, Gemini and APOLLO Spacecraft.

A comparative graph, altitude Vs time from re-entry interface between Apollo, Gemini and a shuttle is shown below.

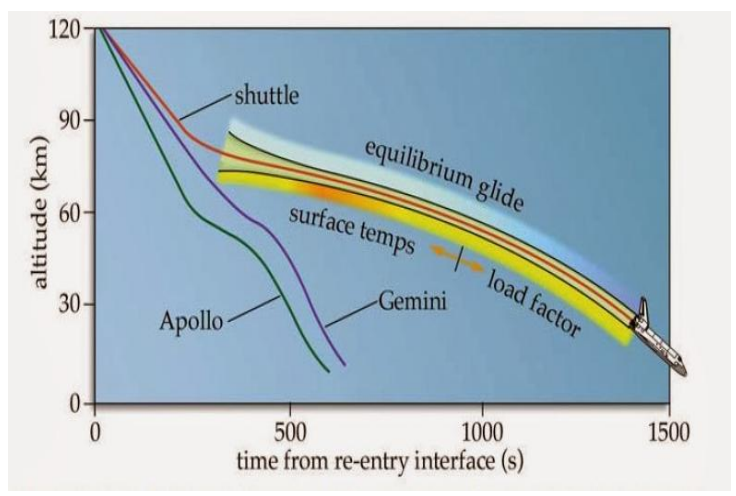

The Thermal soak is made-up of insulating material to radiate the heat away from the Spacecraft.Generally the thermal soak essentially used is made upof ceramic or composite tiles over the rocket'sexternal surface which is made up of carbon material on the highest heat load points like the nose and wing leading edges .Damage to this material on the wing led to the ColumbiaSpace Shuttle Tragedy in 2003. The materials which are conventional can't be used in the heatshield.Exotic materials like reinforced plasticcomposites are used as they have low thermal conductivities, Also they can bear the extreme-entry temperatures like that of 3000 degrees. Thespace shuttles have increased performance at elevatedtemperatures and are lightweight. Additionallythere are already existing methods like Pressure Bag Moulding, high pressuremoulding and tape winding. The ablative material to be selected is based on the Re-entry conditions.Ablation is the removal of materialfrom the surface of an object by vaporisation, chipping or other erosive processes. It is definite that the external layer of the space shuttle will get superheated on reentry but on account of ablation the burning will happen in a Controlled manner causing limited sacrificial erosion of the virgin material of the rocket. If we look at theCross-section of a metal surface on which Ablation Is acting we can see that there is the external metal surface below which there is a reaction zone which primarilyundergoes sacrificial erosion then under that we have the virgin zone that is made up of reinforced plastics andfinally we have the backup structure damage beyond which it leads to the breakdown of the Thermal Shieldof the space shuttle. In ablation the gaseous by-productwhich is left after the sacrificial erosion of the metal surface carries the heat away by convection and the remaining solid metal insulates the space craft fromsuperheated gases.Ablative materials are essentialcomponents of the heat shields for spacecraft's entry into a planetary atmosphere from space and cooling of rocket engine nozzles. The latest ablative materials proposed to be used are the Thermoplastic polyurethaneelastomer nano-composites as alternateheat shielding materials (EHSM'S) in ablative applications. The ablative materials are generally incorporated into the thermal Protection System on the exterior of rockets and also on the exterior of solid rocket motors to protect the essential electrical and structural components of the space craft from superheated conditions. Within the combustion chamber with temperatures greater than 200degrees, heat flux $\left(1400 \mathrm{w} / \mathrm{cm}^{\wedge} 2\right)$. Ablative materials can be hard composite foamsor soft rubber like composites. The basicmechanism of ablation is that when the metal surface gets exposed to the extreme thermalconditions the virgin material undergoes ablativeprocess which leads to charring of the ablative

\section{Volume 4 Issue 11, November 2015}




\section{International Journal of Science and Research (IJSR) \\ ISSN (Online): 2319-7064}

Index Copernicus Value (2013): 6.14 | Impact Factor (2014): 5.611

material on application of pyrolysis from the virginmetal .This pyrolysis is an endothermic reactionhence it in itself absorbs substantial amount of heatgenerated on the heat loading points of the shuttle. There are two products formed during this process of ablation-1) char on the metal surface which acts as an insulating layer for the shuttleand 2) gaseousby-product which further carries some amount of the heat generated by the process of convection. Hence ablation causescontrolled burning of the shuttle surface onre-entry. The present scenario is that Thermoplastic Polyurethane elastomer nanocomposites are used but on the whole we canconclude that the reinforced plastic compositesact as the thermal shield and the interaction of these materials with the superheated external conditions cause less sacrificial erosion sincethe process of ablation controls the surfacetemperature and restricts the flow ofheat into the substrate. Hence the other nameof Ablation is Controlled Sacrificial Erosion.

There are four critical parameters considered when designing a vehicle for atmospheric entry:

1) Peak heat flux

2) Heat load

3) Peak deceleration

4) Peak dynamic pressure

\section{Heat Variation}

Heat variation of a re-entry vehicle having velocity of 8 $\mathrm{km} / \mathrm{h}$ Vs altitude is given below with three different angles.

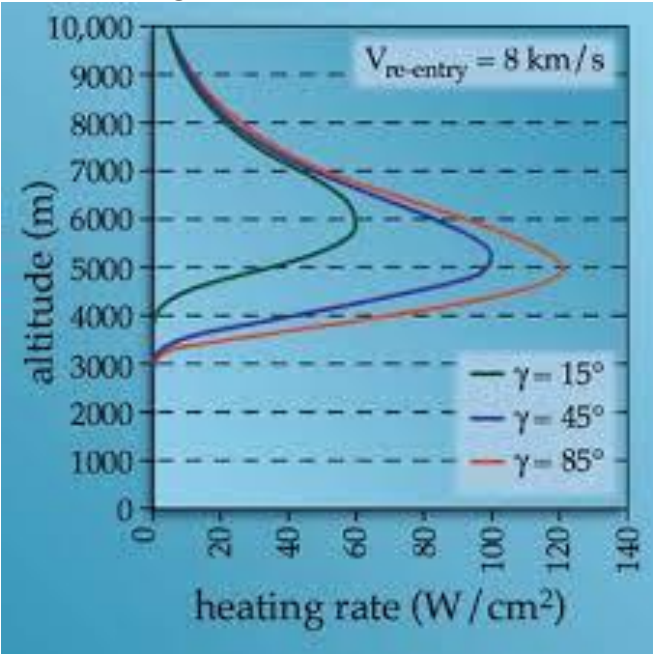

According to above graph, we require ablative materials which can withstand at high peak values.

Hence, following materials can be used for heat protection for a re-entry vehicle: -

1) SLA-561V -SLA in SLA-561V stands for super lightweight ablator. SLA-561V is a proprietary ablative. SLA-561V begins significant ablation at a heat flux of approximately $110 \mathrm{~W} / \mathrm{cm}^{2}$, but will fail for heat fluxes greater than $300 \mathrm{~W} / \mathrm{cm}^{2}$. The MSL aeroshell TPS is currently designed to withstand a peak heat flux of $234 \mathrm{~W} / \mathrm{cm}^{2}$.

2) PICA -Phenolic impregnated carbon ablator (PICA), a carbon fiber preform impregnated in phenolic resin, PICA is a modern TPS material and has the advantages of low density (much lighter than carbon phenolic) coupled with efficient ablative capability at high heat flux. It is a good choice for ablative applications such as high-peak-heating conditions found on sample-return missions or lunar-return missions. PICA's thermal conductivity is lower than other highheat-flux ablative materials, such as conventional carbon phenolics. A single monolithic piece of PICA is sized to withstand a nominal peak heating rate of $1.2 \mathrm{~W} / \mathrm{cm}^{2}$.

3) AVCOAT - AVCOAT is a NASA-specified ablative heat shield, a glass-filled epoxy -novolac system.

4) SIRCA - Silicone-impregnated reusable ceramic ablator (SIRCA) was also developed at NASA Ames Research Center

5) PICA-X - PICA-X was developed by SpaceX in 20062010 for the Dragon space capsule

\section{Working}

The ablative heat shield functions by lifting the hot shock layer gas away from the heat shield's outer wall (creating a cooler boundary layer). The boundary layer comes from blowing of gaseous reaction products from the heat shield material and provides protection against all forms of heat

The overall process of reducing the heat flux experienced by the heat shield's outer wall by way of a boundary layer is called blockage. Ablation occurs at two levels in an ablative TPS (Thermal Protection System): the outer surface of the TPS material chars, melts, and sublimes, while the bulk of the TPS material undergoes pyrolysis and expels product gases. The gas produced by pyrolysis is what drives blowing and causes blockage of convective and catalytic heat flux.

Pyrolysis can be measured in real time using thermogravimetric analysis, so that the ablative performance can be evaluated. Ablation can also provide blockage against radiative heat flux by introducing carbon into the shock layer thus making it optically opaque. Radiative heat flux blockage was the primary thermal protection mechanism of the Galileo Probe TPS material (carbon phenolic). Carbon phenolic was originally developed as a rocket nozzle throat material (used in the Space Shuttle Solid Rocket Booster) and for re-entry vehicle nose tips.

The thermal conductivity of a particular TPS material is usually proportional to the material's density.Carbon phenolic is a very effective ablative material, but also has high density which is undesirable. If the heat flux experienced by an entry vehicle is insufficient to cause pyrolysis then the TPS material's conductivity could allow heat flux conduction into the TPS bond line material thus leading to TPS failure. Consequently, for entry trajectories causing lower heat flux, carbon phenolic issometimes inappropriate and lower density.

\section{Conclusion}

A comparative study done on different ablative materials suitable for thermal protection for re-entry vehicle using heat variation and time from re-entry interface Vs altitude. Simultaneously, SLA-561V, PICA, AVCOAT, SIRCA, 


\section{International Journal of Science and Research (IJSR) \\ ISSN (Online): 2319-7064}

Index Copernicus Value (2013): 6.14 | Impact Factor (2014): 5.611

PICA-Xare found as most efficient materials for heat ablation.

\section{References}

[1] Iposcience.iop.org

[2] RADIATION-ABLATION COUPLING FOR CAPSULE REENTRY HEATING VIA SIMULATION and EXPANSION TUBE INVESTIGATIONS, $5^{\text {th }}$ European Conference for Aeronautics and Space Sciences (EUCASS).

[3] Interdisciplinary Aerodynamics Group, GR-SCI-IAG, EPFL, CH-1015 Lausanne Switzerland

[4] Atmospheric Re-Entry Vehicle Mechanicsby Patrick Gallais

[5] https://www.flightglobal.com

[6] http://www.sciencedirect.com/science/book/978148322 8853

[7] Re-Entry Vehicle Dynamics (AIAA education series) by Frank J. Regan

[8] The Complete Book of Spaceflight: From Apollo 1 to Zero Gravity By David Darlin

[9] An Analysis of Ablation-Shield Requirements for Manned Reentry Vehicles by Leonard Roberts.

[10]www.faa.gov 